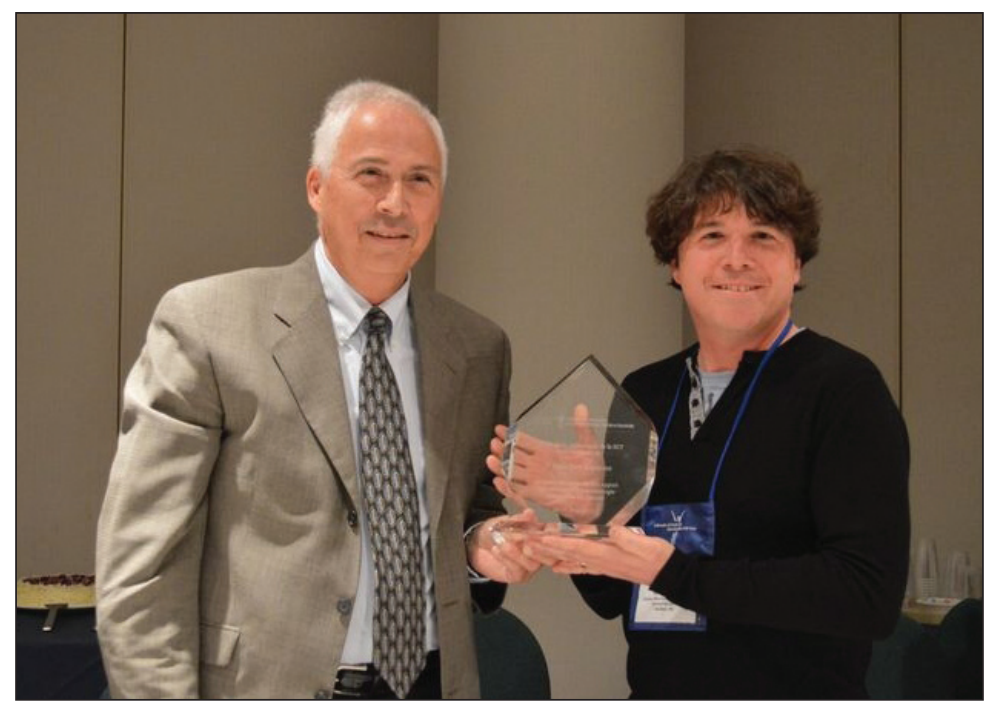

Dr Jean-Guy Lapierre (left) and Dr Patrick Daigneault

\title{
2013 Victor Chernick Award: Dr Jean-Guy Lapierre
}

\author{
Patrick Daigneault MD
}

$\mathrm{T}$ he Canadian Thoracic Society (CTS) Pediatric Assembly is pleased to announce that Dr Jean-Guy Lapierre is the recipient of the 2013 Victor Chernick Award. The Victor Chernick Award, established in 2009, recognizes individuals for lifetime achievement in the field of pediatric respirology. The award was presented to Dr Lapierre at the CTS Pediatric Assembly's annual meeting on April 11, 2013.

This year, when the Canadian Respiratory Conference was scheduled to be held in beautiful Quebec City, I wanted to take the opportunity to honour my mentor Dr Jean-Guy Lapierre by nominating him for the Victor Chernick Award.

Across the rest of Canada, he has always been known as a polite, soft-spoken leader who always asks the perfect question at the end of a conference. In Quebec, and for many pediatric respirologists across the French-speaking world, he has always been an inspiration, a standard, a mentor.
When I first crossed his path, I had sent him a message asking if we could meet to talk about his specialty. I was a pediatric resident with an interest in genetics but respirology was a possibility. After meeting him, there was no turning back. He had passion, a deep desire to always learn more, but there was also a soothing calmness about him. This type of leadership forces everyone around him to aim for more.

Across the meeting room of the pediatric respirology service at the CHU Ste-Justine (Montreal, Quebec) are pictures of all the trainees who were given the best by Guy. These pictures represent a vast array of people from all across Quebec, but also from France, Belgium and Switzerland. We were all taught about spirometry and bronchoscopy, about cystic fibrosis and neuromuscular diseases - but most of all, we were shown how to respect our patients and their family, how to care, really care for them... this is what I will always cherish and try to replicate as best as I can.

Merci Guy. 


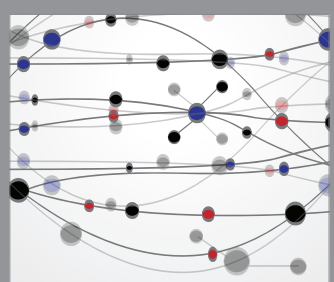

The Scientific World Journal
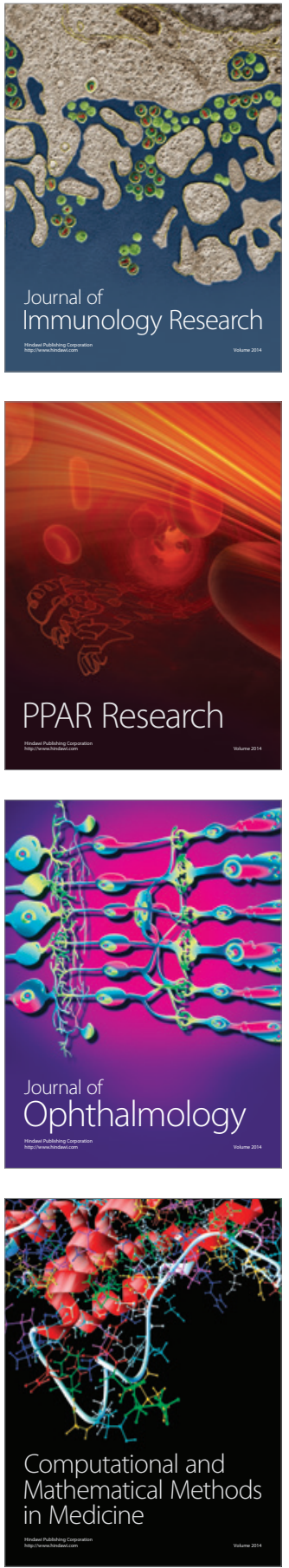

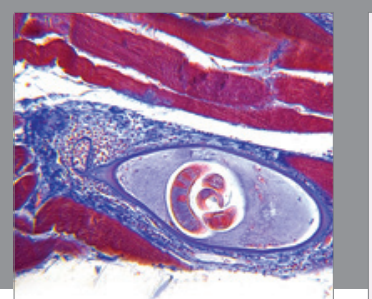

Gastroenterology Research and Practice

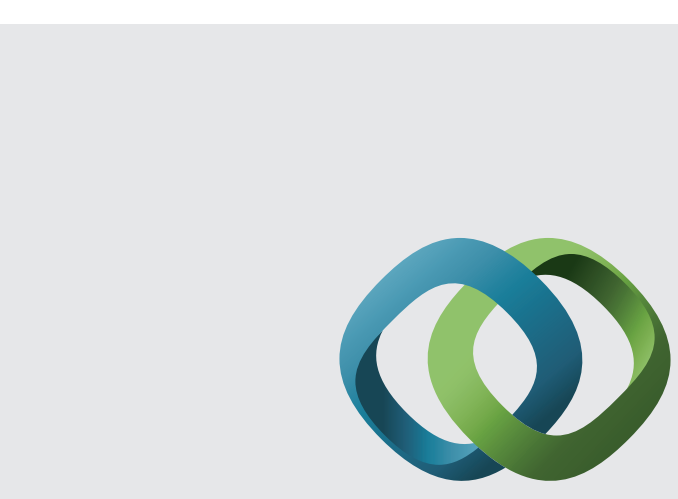

\section{Hindawi}

Submit your manuscripts at

http://www.hindawi.com
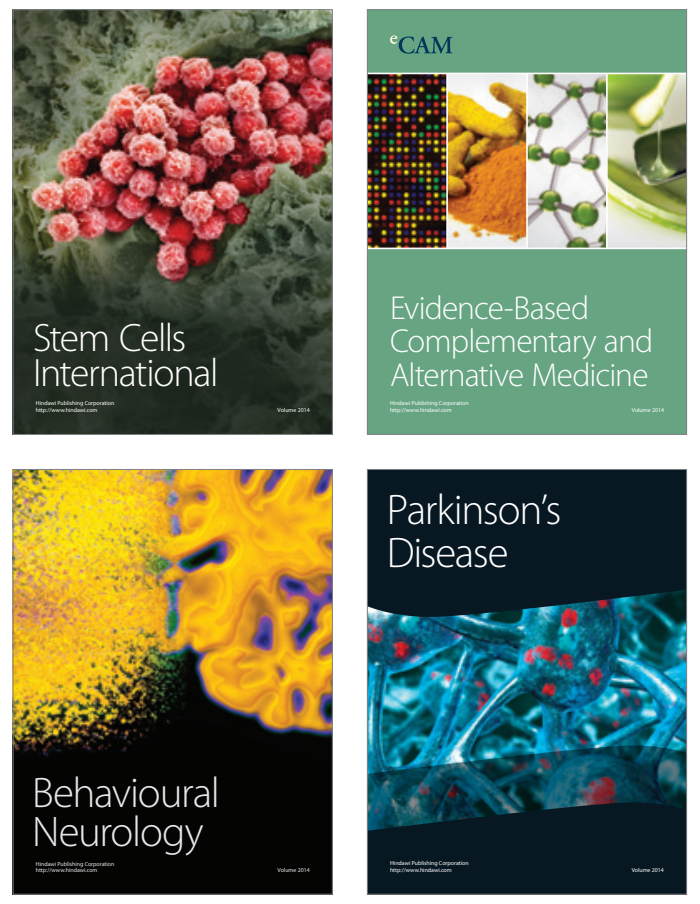
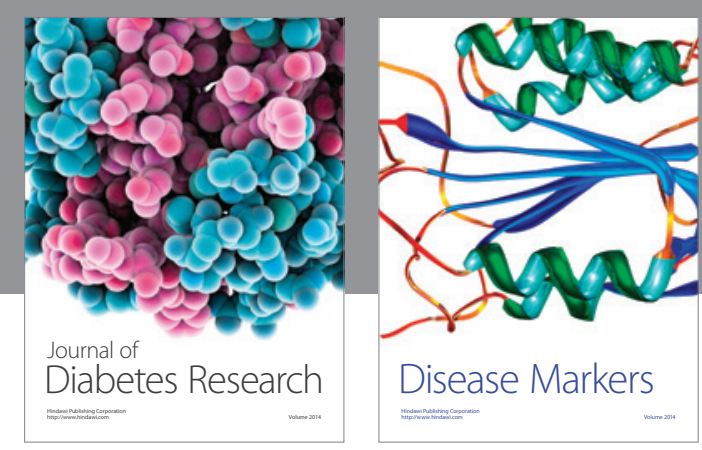

Disease Markers
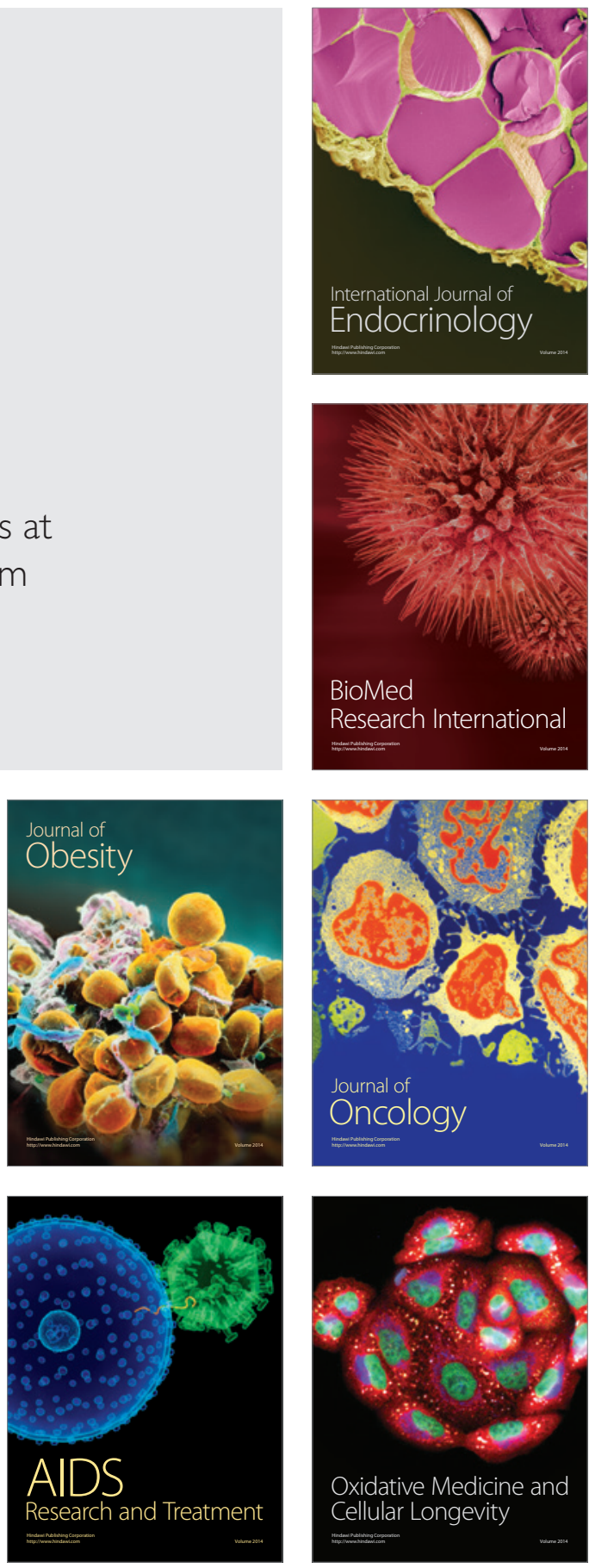